\title{
Undergraduate STEM Students and Community Engagement Activities: Ini- tial Findings from an Assessment of Their Concern for Public Well-being
}

\author{
Alexandra Erwin \\ Dr. Jason Borenstein, Georgia Institute of Technology
}

Dr. Jason Borenstein is the Director of Graduate Research Ethics Programs and Associate Director of the Center for Ethics and Technology at the Georgia Institute of Technology. His responsibilities include administering a Responsible Conduct of Research (RCR) policy for all new doctoral students at Georgia Tech and instructing undergraduate and graduate courses on topics at the intersection of science, engineering, and ethics. Dr. Borenstein is also Editor for Research Ethics for the National Academy of Engineering's Online Ethics Center for Engineering and Science. He is an assistant editor of the journal Science and Engineering Ethics and co-editor of the Stanford Encyclopedia of Philosophy's Ethics and Information Technology section. His research interests include bioethics, engineering ethics, robot ethics, and research ethics. His work has appeared in various journals including AI \& Society, Communications of the ACM, the Journal of Academic Ethics, Ethics and Information Technology, IEEE Technology \& Society, Accountability in Research, and the Columbia Science and Technology Law Review.

\section{Dr. Wendy C. Newstetter, Georgia Institute of Technology}

Dr Wendy C. Newstetter is theAssistant Dean for Educational Research and Innovation in the College of Engineering at Georgia Tech.

\section{Prof. Colin Potts, Georgia Institute of Technology}

Colin Potts is Vice Provost for Undergraduate Education and Professor of Interactive Computing at the Georgia Institute of Technology. As Vice Provost he is responsible for academic support, career advising, the integration of curricular and co-curricular programs, community engagement, curricular planning and the Honors Program. His research areas are requirements engineering, software privacy, and professional ethics.

\section{Ellen Zegura, Georgia Institute of Technology}

Ellen Zegura is the Stephen Fleming endowed chair in Computer Science at Georgia Tech. Her research interests include computer networking, civic data and design, and teaching community engagement. 


\section{Undergraduate STEM Students and Community Engagement Activities: Initial Findings from an Assessment of Their Concern for Public Well-Being ${ }^{1}$}

\section{Introduction}

In response to findings from the Cech study on the "Culture of Disengagement" at American engineering institutions [1], much unease emerged regarding how future engineers might not be developing a mindset that places the public's well-being as a foremost priority. The study indicated that engineering programs negatively impact the attitude that undergraduate students have toward the public [1]. This, of course, could have an important bearing on the type of professionals that an academic institution is sending out into the world and what they think their ethical obligations are to the public. Many explanations are possible for why students become "disengaged", including practical worries about obtaining a job or paying off debt from college. Against this theoretical backdrop, our research team is in the process of investigating what activities may help to combat, or at least mitigate, the trend unearthed by Cech. More specifically, we are seeking to identify which specific facets of community engagement (CE) activities, including service learning (SL), contribute to or fortify the concern that engineering and other STEM students have for the well-being of the public. Our team has embarked on a five-year grant funded project to study the effects of a broad range of community engagement activities, both inside and outside of the classroom.

In this paper, we provide an overview of the $\mathrm{CE}$ and ethics project at the Georgia Institute of Technology (Georgia Tech), including a description of our assessment efforts. We primarily focus here on its quantitative components, which involve the use of an assessment instrument to collect data on how undergraduate STEM students perceive their responsibilities related to the public's well-being. We administered a modified version of the Engineering Professional Responsibility Assessment (EPRA) survey created by Angela Bielefeldt and her team at the University of Colorado Boulder [2],[3]. Our modified version of the EPRA survey, which we call the Generalized Professional Responsibility Assessment (GPRA), was created with the goal of reaching more students in STEM fields than just engineering majors. We discuss initial findings from the first stage of data collection obtained from our primary study cohort, which is the incoming Fall 2017 undergraduate class at Georgia Tech. As the project proceeds, our hope is to collect and share findings that may shape the curriculum at engineering and other STEM institutions.

\section{Theoretical Framework}

The foundation of the EPRA, and thus our GPRA as well, is grounded in the Professional Social Responsibility Development Model (PSRDM) created by Canney and Bielefeldt [4]. The model seeks to gauge "the development of personal and professional responsibility in [students]" and merges these two dimensions together for the professional connectedness realm [4]. The personal social awareness piece relates to the development of one's feeling "a moral or social obligation to help

\footnotetext{
1 This material is based upon work supported by the National Science Foundation under Grant No. 1635554. Any opinions, findings, and conclusions or recommendations expressed in this material are those of the author(s) and do not necessarily reflect the views of the National Science Foundation.
} 
others" while the professional development piece refers to social considerations and understanding the social context of their work [4]. As these two develop independently of each other, the professional connectedness piece cyclically develops as students weigh the costs and benefits of service through action [4]. For example, students can begin to serve through their career specialization and slowly weigh the future benefits of these actions, which may lead to an increasing amount of service engagement [4].

This model is rooted in an ethics of care framework, which is focused on "how a [student] should consider others more intentionally in the... design process [4]." Students, if guided by the ethics of care, may take into consideration the parties who will be impacted by their designs and decisions, and seek to hear these voices during decision making processes [4].

The PSRDM model does not assume that the mindset of students develops in a linear manner. Some of the relevant skills or characteristics do not necessarily emerge early on in life. Students may develop attitudes for each piece (personal social awareness, professional development, and professional connectedness) simultaneously [4]. It is also possible that the development of one piece will influence the development of the other pieces; however, this is not always the case. The PSRDM model serves as the theoretical foundation for the EPRA survey as Bielefeldt and colleagues seek to understand how the engineering curriculum and other experiences impact student attitudes toward social responsibility [4].

\section{Overview of the Project}

Our research team has embarked on a five-year project that seeks to examine how curricular, co-curricular, and extra-curricular CE activities affect student attitudes about their responsibilities regarding the public's well-being. The project has two main research arms: (1) the quantitative ("Breadth") approach, involving the use of survey instruments and (2) the qualitative ("Depth") approach, involving semistructured interviews. The former will be the primary focus here.

Our project focuses on CE, including its SL-related aspects. Although a consensus definition of CE is difficult to find, SL is usually defined in the literature, by the National Service Learning Clearinghouse, as "a teaching and learning strategy that integrates meaningful community service with instruction and reflection to enrich the learning experience, teach civic responsibility, and strengthen communities" [5]. We are interested in SL for two main reasons. The first being that there are efforts to investigate whether SL and volunteering has a positive impact on students in measures of social responsibility [2],[6]. Yet a caveat is that understanding which specific factors contribute to changes in social responsibility attitudes is lacking. Second, engineering and computing programs typically include a capstone project or design-based course as a degree requirement. Our project may shed light on SL components that could be integrated into the design of such courses.

One of our key research hypotheses is that appropriately structured CE actively contributes to the moral maturation of students and facilitates the broadening of their sphere of ethical concern. The "moral distance" between one's actions and the effects of said actions can cause students or others to rationalize that they are absolved from responsibility when wrongdoing occurs. Our hope is that appropriately structured CE 
will begin to forestall that type of rationalization and help nurture student empathy for their local and global communities. Georgia Tech has recently decided to invest substantially in CE opportunities for students. With the changes our institution is making by pursuing its comprehensive CE initiative, we should be able to determine if students across the campus exhibit higher levels of concern for public welfare over time.

\section{The Breadth Approach}

The project's Breadth approach involves administering two modified versions of the aforementioned EPRA, an instrument for measuring professional responsibility. As previously indicated, we collectively refer to these modified versions as the Generalized Professional Responsibility Assessment (GPRA).

One version of the GPRA was distributed to our primary cohort, the incoming 2017 Fall undergraduate class, at the beginning point of their career at Georgia Tech. The students received the survey a few months prior to their first year as an undergraduate. The students had been accepted to attend our institution but had not yet started their courses. The data reported below are from this version of the GPRA survey. Not all of the students' demographic information was directly obtained through the survey; we relied on other sources of data, including from the campus admissions office.

A second, slightly altered, version of the GPRA will be sent to our primary cohort at the mid and end-points of their undergraduate careers. At those points, the survey will also include a section where the students are asked to provide a self-report on CE experiences in curricular, co-curricular, and extra-curricular settings. This will help our research team to identify the types of student CE activities, as well as be able to evaluate the quality of their CE experiences. The plan is to reach these students at a midpoint of their degree program primarily via two courses taken by many STEM majors, a sophomore level Physics class and a sophomore level Math class. The primary cohort will receive the survey a third time upon their graduation. A link to the GPRA will be included within the collection of surveys that students complete during the graduation process.

In addition, we will send the second version of the GPRA to the cohort of undergraduates who receive their degree in each Spring semester for the duration of the project; this started with the group who graduated in Spring 2017. Surveying each graduating class will provide benchmark data.

With the data we collect from the surveys, we should be able to evaluate the student body as a whole and understand whether the undergraduate population displays measurable changes in its concern for public welfare over time. We will utilize the end datasets, starting with the Spring 2017 graduating class, in order to determine whether some form change is taking place over time in the attitudes of graduating seniors.

\section{Initial Findings from the Breadth Approach}

The findings reported in this paper are from the first administration of the GPRA to our primary cohort. We sought to survey all incoming students after they had submitted their initial deposit indicating their intent to attend Georgia Tech in Fall 2017. We partnered with our Office of Undergraduate Admissions on crafting an e- 
mail message that was sent to these students asking them to participate in a survey. The survey was reviewed and approved by the Institutional Review Board (IRB) at our institution. No compensation was provided to these survey participants.

This version of the GPRA has eleven main questions, but many of those questions have multiple parts. Several of the questions utilize a 7 item Likert scale from " 1 Strongly Disagree" to "7 - Strongly Agree". Some of the questions are constructed using negative language, a feature derived from the original EPRA, in order to test whether there is consistency across the students' answers when they are being asked about similar things. We are considering whether to remove the "negative" questions in the subsequent offerings if survey participants have difficulty understanding those questions.

1,287 participants completed the survey out of 2,995 students that received it. Out of those 1,287 students, 857 students correctly answered the question that gauges whether they are paying attention. Only those students who answer that question correctly are included in the data set reported on below. Thus, our participation rate was $28.6 \%$.

Out of the 857 students that were included in our initial data analysis, 454 (about $53 \%$ ) reported that they are planning on pursuing engineering in response to the question "Which profession is closest to what you plan on pursuing in the future?". Computing was the next highest intended profession, with 104 students (12\%). 84 students $(10 \%)$ stated they were entering college with the intent of pursuing Medicine or Health. 78 students (9\%) of students reported Science, 49 (5.7\%) Business or Economics, 37 students (4.3\%) Architecture, Arts, or Design, 20 (2.3\%) Communications, Media, or Entertainment majors, 19 (2.2\%) Law or Public Policy, and 12 students (1.3\%) are either pursuing another profession or are unsure of what they will pursue.

$46.6 \%$ of respondents identified as female, and $53.4 \%$ of respondents identified as male. ${ }^{2}$ In terms of ethnicity, $59 \%$ of respondents identified as White/Caucasian, $19 \%$ identified as Asian, $8 \%$ identified as Hispanic, 5.6\% of respondents identified as Black/African American, 4.2\% identified as Two or More races, and 3.9\% identified as Unknown. $91.5 \%$ of respondents are U.S. Citizens, $6 \%$ are Foreign Nationals, and $2.3 \%$ are Permanent Residents.

It is too early in the project to compare within or across cohorts. Yet with the data collected from the incoming Fall 2017 undergraduates, we wanted to determine if these students answered questions differently across a variety of factors such as gender, ethnicity, or intended profession. We first ran tests to compare male versus female survey results. There are 458 males respondents and 399 female respondents in our first data set. This is a large sample, so to determine if there are significant differences between these two groups, we ran the T-square and Chi-square tests. The results showed that on each Likert question within the survey, there does not appear to be any statistically significant difference between genders.

\footnotetext{
${ }^{2}$ Admissions data from our institution indicate that $43 \%$ of the incoming 2017 Freshman class identify as Female and 57\% identify as Male; thus, our survey respondent pool represents that population rather well.
} 
To analyze the data to determine if there are differences with regard to ethnicity, we ran the One-Way MANOVA test. The test compares each question to each ethnicity, indicating if significant differences are present in how each ethnic group answered. The test showed that there were no significant differences in how each ethnic group answered the survey's Likert questions.

Finally, we ran another One-Way MANOVA test with the future profession that the students intend to pursue. The aim is to determine if different fields have different perspectives on CE at least in terms of how they answered the GPRA survey. This test showed that intended profession had a significant impact on the way students answered the Likert questions. For example, students interested in pursing Medicine or Health scored an average of 6.26, while Engineering scored an average of 5.18, Computing students scored a 4.93, and general science students scored a 5.17. We see a significant difference between medical or health students who answered significantly higher than students going into computing, engineering, or science, indicating that volunteerism is more important to students who plan to join medicallyrelated professions.

Another detectable difference is found in relation to the question asking "People in my intended profession have contributed greatly to fixing problems in the world." Students in Architecture, Arts or Design, Communications, Media or Entertainment, and the Business or Economics all answered significantly lower than those students who are going to be in Computing, Engineering, Medicine, or Science. Students interested in medicine found it significantly more important to use "the skills gained from my intended profession to serve others" (see Figure 1) than students interested in science, engineering, or computing. Medicine or Health students answered a 6.5 average, while Engineering students answered an average of 5.81, Business students answered an average of 5.73, and Computing students answered at an average of 5.46.

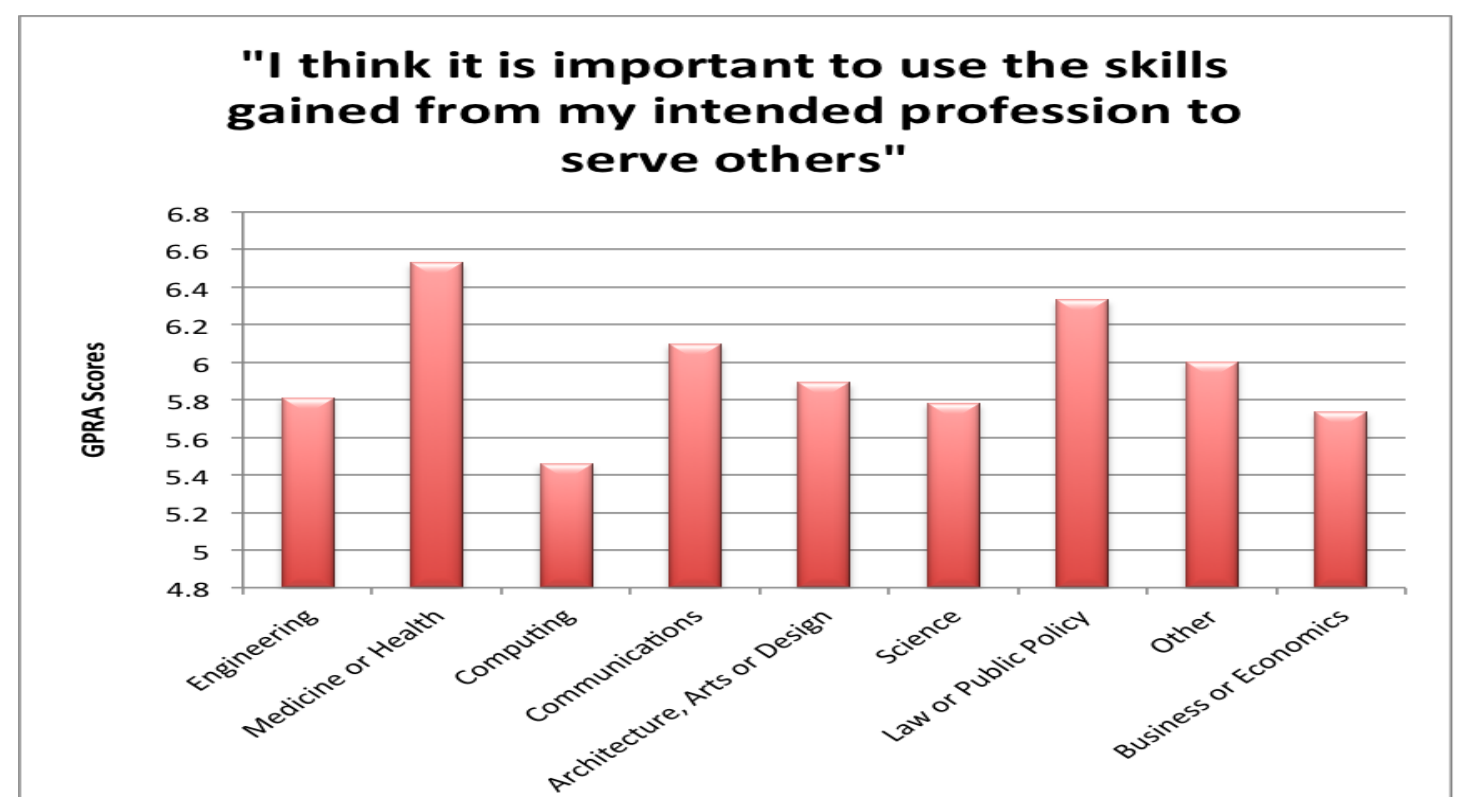

Figure 1 - GPRA scores sorted by the students' reported intended profession 
The medical and health students consistently answered higher than business, computing, and engineering students when it comes to how they view the connection between their profession and service. They also indicate a higher response to the notion that technology could aid society in solving problems than students interested in computing, engineering, and general science did. Moreover, the students interested in medicine or health indicated that "helping others" is a central message in their intended major, a level significantly higher than any other intended major group (see Figure 2). More specifically, students pursing medicine or health answered on average of 6.33, while engineers averaged this question at a 4.83 and computing students answered at 4.05, significantly lower than medical students.

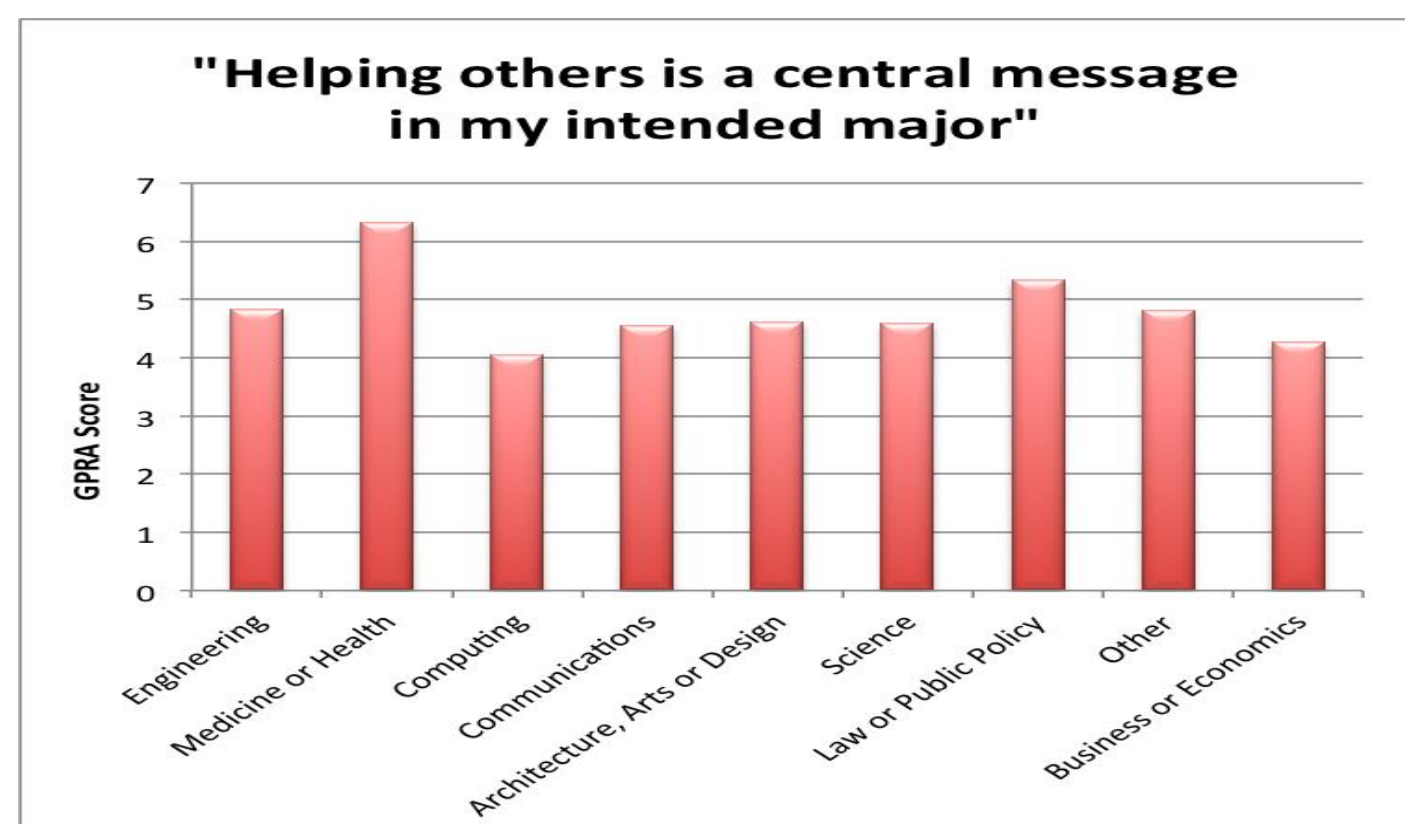

Figure 2 - GPRA scores sorted by the students' reported intended profession

\section{Discussion}

As previously indicated, our findings show that no significant differences are present in survey answers for gender or ethnicity. Yet the findings suggest that a student's intended profession had the highest impact on attitudes toward community engagement. Our initial data shows that those students who are interested in pursuing medicine or health have the highest view of their intended profession and its connection to serving others in comparison to the students in other groups. Computing, engineering, and science had significantly lower answers as compared to students interested in medicine or health, indicating that the former sets of students do not view their major or future profession as being as strongly connected to serving communities and others as medical students do.

\section{Limitations}

The GPRA was administered in an online format only, which can affect response rates and impact how much time respondents take to complete it. Also, some form of self-selection bias may be present in terms of those who complete the survey. For 
example, it is possible that those who do not participate in CE activities may be less willing to respond. Moreover, an equal distribution of students across the different fields is lacking; more than half of the participating students expressed that they plan to pursue engineering.

Although the EPRA, the survey on which the GPRA is based, did undergo a formal validation process [4], the GPRA itself has not yet been validated directly. The GPRA has undergone review by an expert in survey design on our campus, who indicated that our modifications are likely modest enough that we may be able to rely on the EPRA validation. Yet our team is continuing to confer with survey experts, which will inform decisions about further validation.

\section{Conclusion}

In this paper, we reported on some of the initial findings from a survey that is part of our community engagement and ethics project. The project is still at a relatively early stage, but initial indications seem to show that students' professed choice of future profession may have an important connection to their attitudes about the public's well-being.

\section{References}

[1] Cech, E. A. (2014). "Culture of disengagement in engineering education?" Science, Technology \& Human Values 39(1): 42-72.

[2] Bielefeldt, A. R. and N. Canney (2016). "Changes in the social responsibility attitudes of engineering students over time." Science and Engineering Ethics, 22(5):1535-1551.

[3] Canney, N. and A. Bielefeldt (2012). "Engineering students' views of the role of engineering in society." American Society for Engineering Education.

[4] Canney, N. E. and A. R. Bielefeldt (2016). "Validity and reliability evidence of the Engineering Professional Responsibility Assessment Tool." Journal for Engineering Education 105: 452-477.

[5] Seifer, S. D. and K. Connors, Eds. (2007). Community Campus Partnerships for Health. Faculty Toolkit for Service-Learning in Higher Education. Scotts Valley, CA: National Service-Learning Clearinghouse. https://ccph.memberclicks.net/assets/Documents/FocusAreas/he_toolkit.pdf.

[6] Canney, N.E. and A. R. Bielefeldt (2015). "Volunteerism in engineering students and its relation to social responsibility." American Society for Engineering Education (ASEE) Annual Conference \& Exposition Proceedings. 14-17 June. 